Article

\title{
Food Secure Metropolitan Areas: The Transition Support System Approach
}

\author{
Marijke Dijkshoorn-Dekker *, Vincent Linderhof ${ }^{\circledR}$, Thomas J.M. Mattijssen and Nico Polman \\ Wageningen Economic Research, Wageningen University Research, Prinses Beatrixlaan 582, \\ 2595 BM Den Haag, The Netherlands; vincent.linderhof@wur.nl (V.L.); thomas.mattijssen@wur.nl (T.J.M.M.); \\ nico.polman@wur.nl (N.P.) \\ * Correspondence: marijke.dijkshoorn@wur.nl
}

Received: 4 June 2020; Accepted: 26 June 2020; Published: 3 July 2020

\begin{abstract}
Metropolitan areas are highly complex systems where a transition towards food security encompasses a systematic change in the whole food chain. Existing decision support tools that have been developed to inform policy-makers are mostly data-driven but hardly consider the activities and preferences of different stakeholders in the food system. The aim of this article is to contribute to urban food security by combining stakeholder participation with model-driven decision support. For this purpose, we developed and tested the Transition Support System (TSS) approach. In this TSS approach, decision support tools and participatory processes are mutually employed to promote urban food security in an ongoing, stakeholder-inclusive and reflexive process of governance. Our application of the TSS approach in two contrasting case studies highlights how this can contribute towards the development of new perspectives on urban food security, building a joint agenda towards the future and better (mutual) understanding of the issues at stake. We conclude that promoting a transition in the urban food system demands joint learning and reflexive evaluation in order to adapt governance, requiring researchers to play a supporting role in a broader process of change.
\end{abstract}

Keywords: metropolitan areas; food security; decision support; system innovation; transition management; stakeholder participation; social innovation; reflexive evaluation

\section{Introduction}

The growth and expansion of metropolitan areas is a worldwide phenomenon. An increasing percentage of the world's population (currently 55\%) is living in urban areas, and the world's urban population is expected to surpass 6 billion people, around $68 \%$ of the global population, in 2050 [1]. This growth brings important challenges for sustainable urbanization as social, environmental and economic living conditions in many urban regions are under pressure [2]. In this context, urban food security, environmental sustainability and the well-being of the urban population are seen as key factors to successful urban development [3].

With the adoption of the United Nations' New Urban Agenda in 2016, a new global standard for sustainable urban development has been set [3]. Among other things, this New Urban Agenda urges national governments and local authorities to provide nutritious food to all their citizens. Current issues with urban food security relate to both the quantity and quality of available food [4,5]. Issues such as malnutrition, obesity, hunger, nutrient deficiencies and the affordability of good quality food are important topics in this context, but environmentally sustainable food production and a reduction of food waste are also of key relevance [3,5]. Food and nutrition security is a multidimensional concept and the definition has four dimensions: (i) the availability of food; (ii) accessibility of food markets; (iii) food utilization, which is includes the nutritional value, social value and food safety; and (iv) the 
stability of food security over time [6]. The urban aspects of food security have not received much attention yet, especially in low- and middle-income countries [7,8].

Over recent years, several initiatives have taken place in order to promote a more sustainable urban food system. A prominent example is the Milan Urban Food Policy Pact. In this pact, more than 180 cities and regions from all over the world have committed to developing sustainable food systems which provide healthy and affordable food to all people while minimizing waste and biodiversity loss [9]. At the UN Habitat III meeting on sustainable urban development in 2016, many organizations and countries put food security high on the agenda and urged for action to promote this security [10]. Various European cities are now taking up a proactive role in urban food system transformations, as presented at the Fifth Annual Gathering and Mayors' Summit of signatory cities in Montpellier (France), November 2019. These developments encourage transitions towards a more sustainable development of metropolitan areas with access to safe and nutritious food.

The main aim of this article is to contribute towards urban food security in metropolitan areas by combining the need for stakeholder participation in model-driven decision support to develop transition pathways [11,12]. For this purpose, we will present a stakeholder-inclusive approach to decision making in food system transitions: the Transition Support System (TSS) approach. In this TSS approach, decision support tools and participatory processes are mutually employed to support urban food security. As we will show in this article, there are important benefits to combining stakeholder-based and modeling-based methods in promoting food system transitions contributing to better informed decision making in a dynamic context where unforeseen factors and new priorities of stakeholders can be included. Our TSS approach also aligns with the UN's New Urban Agenda, which envisages an involvement of stakeholders in transformation of the urban food system.

Section 2 introduces the materials and methods which form the basis of this article. This is followed by Section 3, which introduces the main points of departure for our TSS approach. Based on the literature, a number of important principles for this approach are identified and discussed, and based on these, the TSS approach is introduced. Section 4 discusses the practical applications of this approach as a process of small steps. Section 5 will explain how the TSS approach has been used in practice and showcase its employment in two case studies. This article is wrapped up with a discussion and conclusion in Section 6.

\section{Materials and Methods}

The material presented in this article is based on a study of the literature and discussions with stakeholders and experts, as well as on an empirical application of the TSS approach in two case studies. This research was not implemented through a systematic and linear process, but should rather be seen as an iterative exercise where lessons from literature, workshops and stakeholder feedback were employed in order to develop and improve the Transition Support System approach which we will present in the following sections.

First, an integrative study of literature was conducted. In contrast to a structured review of literature, this type of study does not aim to systematically cover all articles ever published on a certain topic or within a certain field of research. Rather, it aims to combine and integrate perspectives and insights from different scientific domains or research traditions [13]. For such purposes, a strict and structured approach can hinder a more creative, cross-cutting, conceptual and integral contribution. In this context, an integrative study of literature is preferable [13]. Such a study of literature should advance conceptual or theoretical frameworks instead of providing an overview of a research area. This often demands a more creative and flexible collection of data in comparison to a structured review of literature [13].

In this way, rather than providing a systematic overview of literature on urban food security or stakeholder inclusion in transitions, our work in this article presents a meta-narrative which identifies a number of main building blocks for promoting urban food security (Section 3) and develops this into a conceptual and methodological framework (Section 4). Relevant literature was identified through 
a search in scientific databases (Google Scholar, Scopus and the Web of Science) and also collected via colleagues and peers. Following the broad scope of this integrative study, the literature was not collected through fixed sets of keywords, but by exploring many different topics and research domains. Based on this initial collection of literature, a snowball method was also applied to collect additional information via references cited in the articles that were initially collected.

The TSS approach was applied and tested in two contrasting case studies presented in Section 5. The purpose of these case studies is to show the applicability of the approach in real life situations [14]. Including more cases was beyond the aim of illustrating applicability and would also provide less space for in-depth analysis and description in this article. One case was employed in the Dutch province of Overijssel and the other in the metropolitan region of Accra (Ghana). The Overijssel case was established because the policy-makers of the densely populated province of Overijssel were searching for innovative ways to improve the sustainability of the agricultural sector in the province (reducing greenhouse gas emissions in a Western European country). In the Accra case, earlier research projects had indicated the huge challenges that Ghana faces with the high degree of urbanization of its capital, Accra in a developing context $[15,16]$, and this was followed up by the case study described in Section 5 .

As the inclusion of stakeholders in both cases was part of the research experience, we will provide more details on this process as part of the elaboration of the TSS approach in Sections 3 and 4. In Section 5, we will explain which stakeholders were involved throughout the process and in what way they were involved. In both case studies, co-creation meetings with stakeholders were organized depending on the issues at stake in the period 2017-2019.

\section{Transition Support System Approach: Points of Departure}

In this section, we will show the importance of involving stakeholders in informal governance processes, social innovation and the co-production of knowledge in food system transitions. When applying decision support tools, this approach will result in better-informed decisions and improve the quality of deliberation in which stakeholders are continuously engaged.

\subsection{Stakeholder Involvement in Food System Transformation}

A transition is seen as a structural societal transformation, where existing practices and institutions substantially change or are replaced by alternative ones [17]. Such a transition is often a combination of technological, economic, environmental and/or social shifts, which together lead to a substantial change in regime $[18,19]$. This regime is understood as the common practices in which people engage as well as the generally accepted formal and informal rules and prevailing policies. An example of a past food system transition is the intensification of Western agriculture after World War II: the increased availability of artificial fertilizer, technological developments, policy support for intensification, new financing mechanisms for entrepreneurs, the increased internationalization of supply chains, education of farmers and many other aspects have led to agricultural practices that were vastly different from the pre-war regime.

The transition envisaged in the New Urban Agenda comprises technological changes in the food system, but is also related to social innovation and stakeholder participation. A transition in the food system is a non-linear, multi-stakeholder process that crosses different scientific domains [20]. Transition literature recognizes that most transitions do not follow a linear and predictable pathway, but are unpredictable and complex processes in which diverse societal forces come together [21,22]. In this context, urban sustainability challenges are increasingly linked with social innovation and grassroots movements [19]. A transition arises through a combined effort of diverse actors within and outside of formal boundaries.

In the (urban) food system, citizens and other societal stakeholders play a potential role in a transition through shifting behaviors as consumers of products, creating more demand for sustainably produced and good quality food [23]. However, citizens are not only consumers: they are also active agents who promote change throughout the food chain and engage in social innovation in the 
production and distribution of food [23]. A prominent example of this is the rise (or revival) of urban agriculture across many Western cities in the past decade, in which citizens, local non-governmental organizations (NGOs) and social enterprises have played a prominent role [24].

Modern cities are also highly complex systems, where sustainability transitions are multi-sectoral, multi-actor processes that are conditioned by existing infrastructures [25]. A transition towards food security is not merely a shift in consumer preferences or in food production: it encompasses a systematic change in the whole food chain from the primary producer up to the end-consumer [26]. This means that many actors have a stake: farmers, farm advisors and suppliers, NGOs and citizen groups, brokers, retail-stores, food transporters, food consumers, authorities, and researchers. This illustrates that-also from an actor perspective-a transition in urban food security is linked to many different societal interests.

Yet, when one looks at how policy decisions are made and knowledge is created, many innovation processes in the urban food domain are still largely expert-driven. Stakeholder participation has often been limited to an involvement in agenda-setting, with little stakeholder involvement in knowledge creation, decision making and (policy) evaluation [27]. Existing decision support tools that have been developed to inform policy-makers are mostly data-driven but provide little account for the activities and preferences of societal stakeholders. Such a linear approach to create and apply knowledge does not align with the complex nature of societal transitions, which requires stakeholder involvement and mutual learning at all stages [20]. As a result, these existing decision support tools overlook the importance of informal governance processes, social innovation and the co-production of knowledge in bringing about societal change.

\subsection{From Decision Support to Transition Support}

A decision support tool is a computer-based model that helps policy-makers, spatial planners and business managers in making decisions regarding complex issues. Decision support tools are popular for policy-makers who have to make decisions with long-term impact (food security and climate change). Usually, such tools provide ex-ante evaluations, informing how the world is likely to change after an expected intervention through projections of the future-often projecting the impact of different potential decisions at stake [28]. For example, a decision support model can help to predict changes in land use as a consequence of tax measures [29]. With this, decision support tools can aid in envisioning the actions that promote transitions towards food security.

The literature highlights how formal decision-making processes and (scientific or technological) innovations can steer towards transformations in society. Scientific knowledge and decision support models play an important role in allowing policy-makers to make well-informed decisions towards a sustainable future. However, the important role of societal stakeholders and their activities in promoting sustainability transitions is also highlighted [19]. A transition is not merely a product of innovation and decision making: it is a change of a system that arises through a combined effort of diverse stakeholders. In the current networking society, this demands authorities and scientists to engage with a broad range of stakeholders in order to contribute towards sustainable development [30]. For these reasons, we advertise a shift from the employment of decision support tools towards transition support processes which combine decision support with stakeholder involvement over a longer period of time.

Methodologically, the combination of decision support with stakeholder involvement is also of added value. Decision support tools often focus on quantitative approaches. The integration of these approaches with qualitative perspectives is necessary to link to different understandings of the issue at stake and of the potential interventions to address this issue. The combination of qualitative and quantitative data utilizes the complementarity between different types of knowledge and allows for a better linkage and "translation" of stakeholders' priorities and policy objectives with quantitative decision support tools. The literature refers to multiple tools combining qualitative and quantitative approaches. For instance, tools for assessing the implications of changes in agro-food systems can 
combine scenario analysis with linear programming in order to assess possible scenarios for a regional agro-food system [31].

There are important benefits to combining stakeholder-based and expert-based methods in promoting food system transitions [32]. These include a potential to increase societal support for decisions that are being made [33], a potential to increase the active contribution of stakeholders towards promoting societal change [34], the identification of new issues by stakeholders [32], increased quality of decision making [35], and a more effective and efficient formulation of policy [36]. By employing decision support tools, stakeholders are supported to take well-informed decisions and the quality of deliberation can be improved. In the urban food chain, a combination of participatory approaches and dynamic models can ensure resilient decision-support tools for promoting sustainable agriculture [37]. However, stakeholder involvement does not improve decision making by definition: it could also have negative impacts because of conflicting preferences or wrongly organized participatory processes $[33,35]$.

\subsection{Governance Processes}

The combination of stakeholder-involvement and expert-driven decision support tools is the point of departure for the Transition Support System approach which we present below. With our Transition Support System approach, we foresee that in promoting urban food security, knowledge development and decision support should be integrated in a continuous participatory process where stakeholders are involved in agenda setting, decision making, implementation and evaluation. In this process, decision support be integrated in a collaborative governance approach that involves stakeholders in moving towards food security in metropolitan areas worldwide. Our transition support approach consists of two main building blocks: (i) process support and (ii) decision support (Figure 1).
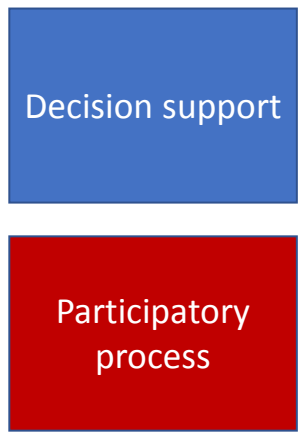

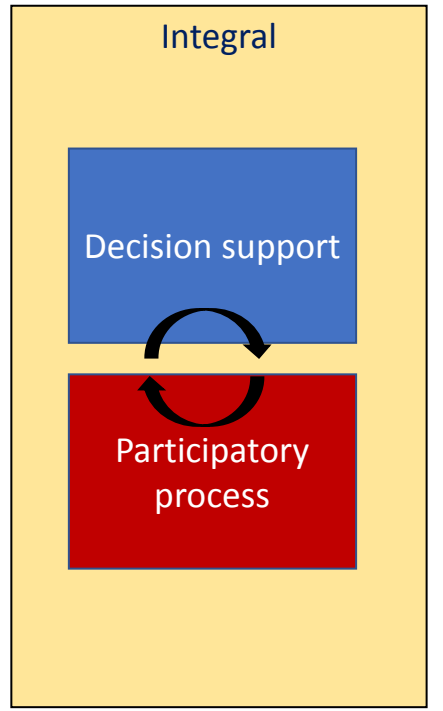

Figure 1. Assessment approaches for food security pathways (source: authors adapted from [38]).

Over time, researchers and policy-makers have become increasingly aware that the steering of transition processes requires continuous adaptation and adjustment [21]. In recognition of this, the process dimension of our TSS approach is closely connected to insights from the literature on reflexive evaluation [39] and transition management [40]. Both the decision support tools and transition support processes are flexibly selected and employed, depending on the preferences of stakeholders, political and ecological context, and the specific food security issues at stake.

Transition management provides a system-thinking governance approach for promoting change in contexts that involve multiple domains, actors and levels of scale [40]. This aims to nurture or upscale social and technological innovation in order to promote a more socially and environmentally sustainable regime. While its name would imply that a transition can be managed, transition management is in fact 
more of a steering approach that aims to build consensus and promote sustainable innovation through deliberation [34]. In this, it specifically focuses on bringing together "innovators" or "frontrunners" and on promoting the mainstreaming of social and technological innovations [17,22].

Reflexive evaluation (also referred to as reflexive process monitoring) is an approach in which stakeholders are continuously engaged during the monitoring and evaluation of processes of change. In order to address complex societal problems, this type of evaluation is characterized by emergent design, learning processes between diverse actors and adaptive management [41]. Reflexive evaluation should support and maintain reflexivity in order to be able to deal with uncertainties and conflicts, while at the same time allowing space to challenge current practices. This more action-oriented form of evaluation allows for flexibility to move along with (partly unpredictable) developments in transition processes and explicitly provides a voice to stakeholders in the evaluation of interventions. Because reflection and learning are seen as integral parts of a transition process, lessons learnt along the way can be incorporated in the further process of transformation [39].

Transition support does not merely imply an occasional consultation of stakeholders: it entails a process of regular stakeholder involvement over time. In the field, it has been observed how stakeholder participation - if any-is often limited to an involvement in agenda setting, decision making and policy implementation [42]. Several scholars argue that this involvement of stakeholders in policy evaluation is also of key importance. Knowledge is not neutral: the process of research and evaluation is often influenced by human interests [43]. The result is that knowledge production reflects power and social relationships within society. Managing transitions inherently also leads to democratic tensions [44]. An important purpose of knowledge development should be to accurately represent the interests of different societal groups, including those who are marginalized. This calls for an inclusion of stakeholders in the entire research process-from the setting of agendas up to the evaluation of policy outcomes [45].

\section{The TSS Approach: A Transition Process in Small Steps}

The process of the Transition Support System approach is illustrated in Figure 2. This figure is built upon the principles introduced in the previous section: approaching food system transformation from an integral, multi-stakeholder perspective; a combination of decision support tools and stakeholder participation in knowledge processes; and an interactive involvement of stakeholders throughout different phases of the governance process.

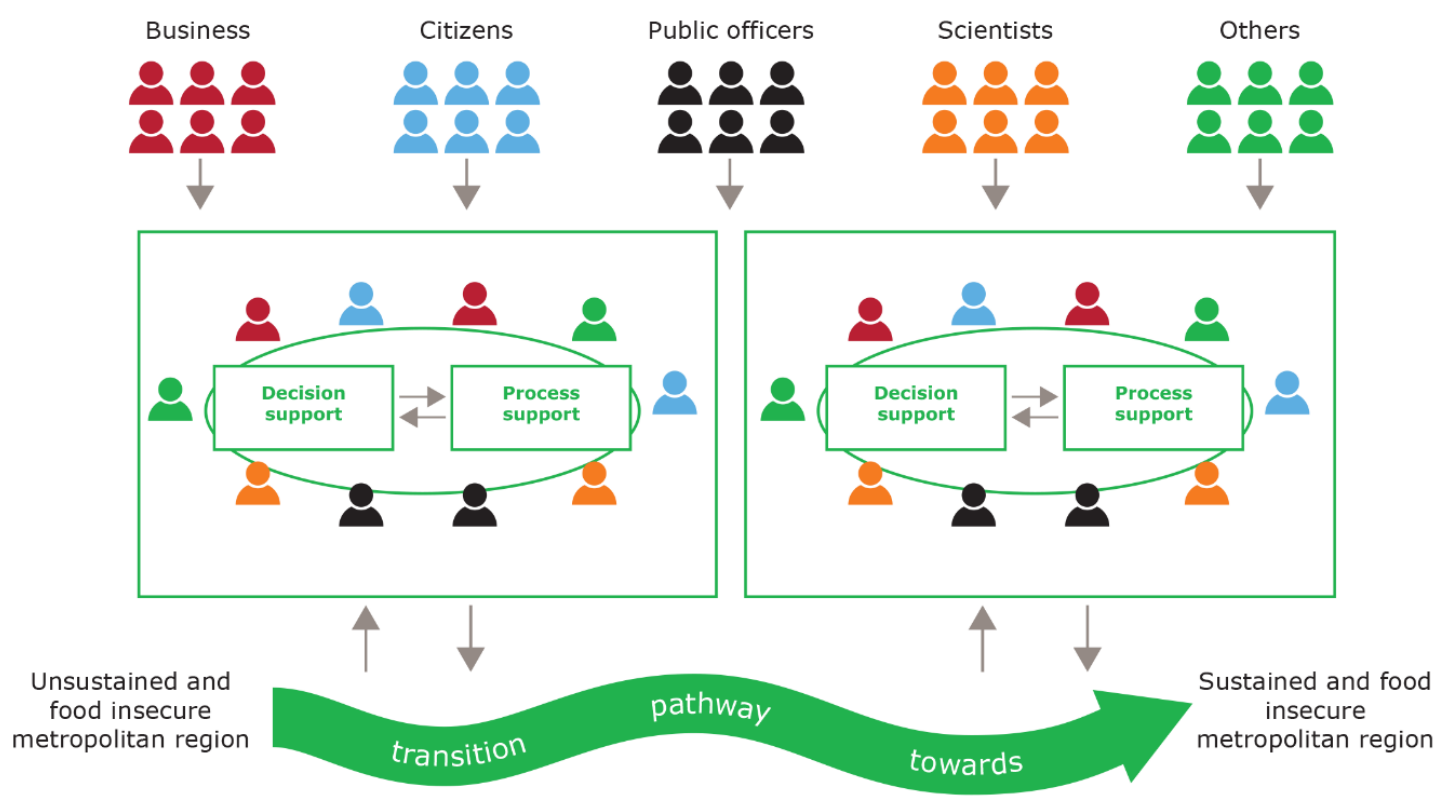

Figure 2. Stakeholder interaction in the Transition Support System (TSS) approach [38]). 
At several points during this process, scientific knowledge and social or technological innovations are discussed and debated with stakeholders, generally aided by the use of decision support tools. The agenda at stake is regularly updated in order to reflexively adapt to unforeseen factors and new priorities from stakeholders. During this process, stakeholders can join or leave at any given time and-depending on issues at stake-different decision support tools can be employed in order to underpin the developments and impacts of interventions. Discussions with stakeholders provide input to scientists and policy-makers that can help them in developing solutions that promote urban food security but are also embedded in society. This is an ongoing circular process of small steps during different stages of an ongoing transition. Eventually, after a longer period of time, this process should lead to sustainable food secure metropolitan solutions.

The methods and tools employed in our TSS are not set in stone: different food systems in varying socioeconomic contexts might require different approaches and different tools. Generally speaking, however, each iteration of the TSS consists of five steps (Figure 3). These steps all involve relevant stakeholders and should be continuously and iteratively conducted: step five is again followed by step one to work towards a secure urban food system in a stepwise and iterative manner.

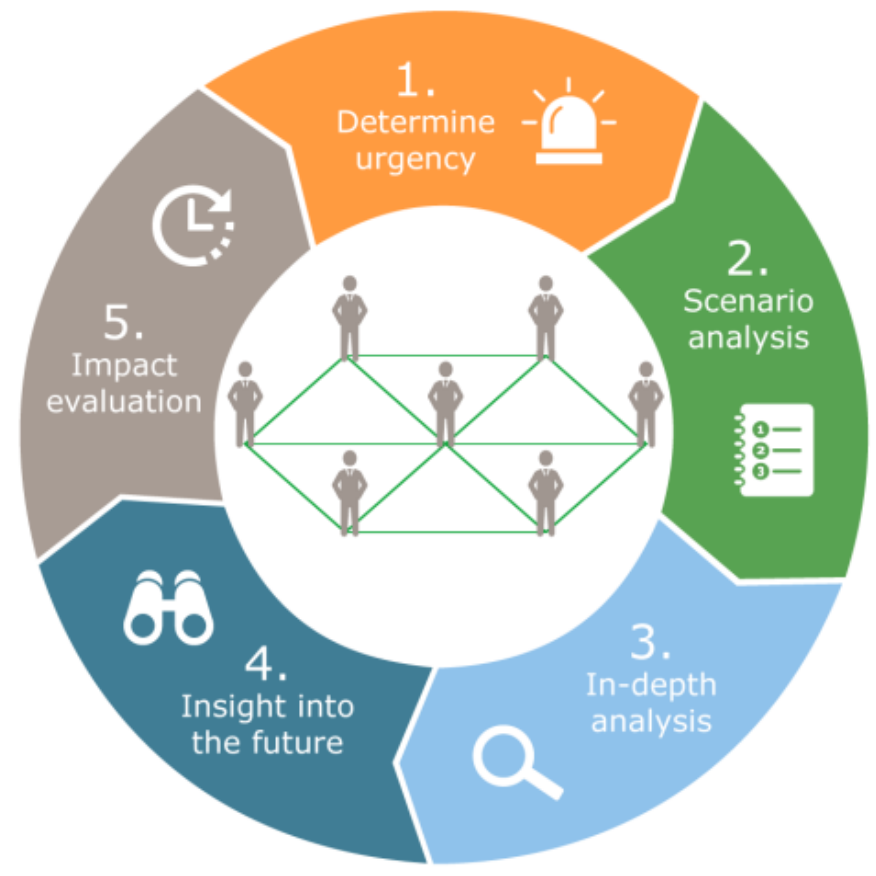

Figure 3. The five steps of the TSS approach [46].

\subsection{Determine Urgency}

The New Urban Agenda [3] and Milan Urban Food Policy Pact [9] both stress the importance of food system transformation in the city. In order to involve stakeholders in this transformation, there needs to be a sense of urgency amongst them-otherwise, why would they participate? The starting point for applying the TSS should therefore lie with identifying relevant topics that provoke a shared sense of urgency amongst stakeholders. This does not mean that these stakeholders need to have a shared agenda, but they should be motivated to address this topic. Pressing issues in the urban food system can be identified and addressed in consultancy with various public and private stakeholders and cover various topics. For answering such questions, an evaluation of policy, societal trends and the position of relevant stakeholders is important. On the basis of such an analysis, a broader group of stakeholders can be identified and invited to engage in the TSS process. 


\subsection{Scenario Analysis}

To progress from a sense of urgency towards a (shared) vision for food secure cities, deliberation with stakeholders is of vital importance [34]. In this, stakeholder-based scenario, analyses can lead to a better understanding of the issues at stake and open up discussions about potential futures and the changes that are required to come to a new urban food system [47]. In this second step, several scenario-based decision support tools can therefore be used to gain insight into potential futures [31] and facilitate discussions about desired views. By projecting different options and analyzing scenarios, the desirability of future developments can be discussed with stakeholders, including an assessment of potential courses of action towards their ideal futures.

\subsection{In-Depth Analysis}

In order to progress from a vision of desirable futures towards an assessment of the potential impacts of various courses of action, a variety of models can be employed in various spatial analyses. With such analyses, decision support tools are used to spatially and/or numerically project various visions of the future [31]. While this step is strongly rooted in expert-based modeling, this should form the basis for a deliberation with stakeholders as it provides valuable information about the issues at stake and future perspectives in regard to these issues. For such an in-depth analysis, a combination of quantitative and qualitative methods and techniques should be employed, also tailored to the spatial scale (national, regional or local) on which urgencies have been identified. The aim should be to maximize complementarity between different types of knowledge and better link stakeholders' priorities and policy objectives with quantitative models [32]. This step should provide insight into diverse scenarios for the future, for example: how does growth of the urban population influence the demand for and production of food and what effects does this have on food prices?

\subsection{Insight into Future Pathways (Chosen Strategy and Policy)}

After the in-depth analysis, the next step should provide visual insight into the effects of different courses of action in order to contribute towards stakeholders' understanding of the impacts of such actions. As discussed previously in this article, transitions are difficult to steer and predict as they are complex, long-term processes [21,22]. Visualizing the potential outcomes of different courses of action can help stakeholders to obtain a better grasp on these issues and discuss the complex interlinkages between different factors. Again, this should form the basis of an interactive discussion: in a set of meetings, points of departure for urban food security and the potential of certain interventions or actions can be discussed with stakeholders, supported by the analysis in the previous steps in which the potential effects of certain actions have been projected. Jointly, it can then be debated which effects are desirable, which other impacts might be associated with this, and whether other courses of actions are preferable. This can lead to a shared action perspective and a potential fine-tuning of, or change in, the models and data that are part of the decision support in order to adequately address these priorities.

\subsection{Impact Evaluation}

After the impact of certain actions has been projected ex-ante, it is important to also monitor the effects or interventions during and after these have been employed. After all, aiming for societal change requires constant evaluation and adaptation in governance [34]. For this reason, it is important to closely monitor the ongoing changes that are taking place in the urban food system so that policies and actions can be adapted [41]. In this fifth step, chosen strategies and changing policies will be evaluated together with stakeholders: what are the experienced and measured consequences of actions and how do these effects relate to the projected and desired impacts? The feedback provided by stakeholders in this step also links back to the decision support tools: how can these tools be used and improved to promote urban food security and help in coming to new spatial insights and effects? During the 
evaluation, new urgencies and issues can be discussed with stakeholders for a new iteration of the TSS approach until, eventually, the desired urban food security impacts have been realized.

\section{Results}

The TSS approach has been applied in two case studies. The main purpose of this is to show the applicability of the TSS approach. Given that the TSS approach is relatively new, we have not been able to explore a transition process from the beginning to the end, if such a beginning or end could even be pinpointed. Because transition processes typically take many years, our own reporting of such a transition should also be an iterative process with multiple iterations over time, in line with principles from the TSS approach.

\subsection{Sustainable Food System for Urban Areas in Overijssel (The Netherlands)}

Overijssel is a province with 1.1 million inhabitants in the eastern part of The Netherlands. About half of the population lives in the five major cities of the province, spread across three large urban regions: Almelo, Deventer, Enschede, Hengelo, and Zwolle. While the province is quite densely populated, Overijssel is known for its agricultural landscape. More than $70 \%$ of the rural area is used for agriculture, which illustrates the high spatial impact of this sector. While the three urban networks are the driving forces behind the regional economy, the agricultural and food sector are important economic pillars and account for $10.0 \%$ of the regional GDP and $6.8 \%$ of regional employment. Climate change, ambitions for promoting livable and healthy cities, and challenges for sustainable food provision in these cities are cited by policy-makers as important motives to change the current food system. In the provincial future vision for the physical environment for 2030, the importance of a sustainable food system which remains competitive is highlighted [48].

The TSS approach has been employed in order to discuss the road towards such a food system. Together with representatives of the province Overijssel, the involved researchers identified and selected the relevant stakeholders based on their position within the food system. Based on this initial analysis, representatives of the province of Overijssel, farmers, food processing industries, NGOs and citizens were invited for three sessions which were organized in November 2017, July 2018, and October 2018. For each session, different stakeholders were involved based on their interests and knowledge. Discussions during these sessions were focused on reducing regional agricultural production, fewer international transport movements, less environmental pressure, changing cropping patterns, and healthier diets.

During the first meeting in November 2017, global scenarios were translated by the stakeholders into a provincial future vision for 2050 in which the supply of dairy products would equal the provincial demand (no export). Potential action perspectives towards this future were identified and discussed with stakeholders. During the second meeting in July 2018, these action perspectives were made transparent by the researchers through the use of virtual production maps (see example Figure 4, see for more details on databases and software use [27]). These maps provided insight into the potential spatial, environmental and economic effects of action perspectives and formed the basis for further discussion during the workshop. During this meeting, stakeholders expressed that they preferred an integral system approach towards sustainable food production instead of a sector-by-sector approach. Furthermore, a switch from actual consumption towards a healthy consumption pattern was preferred for the provincial future vision. These findings were further explored and translated into future pathways in the third meeting in October 2018.

In the current situation, dairy products are produced all over the province of Overijssel (see Figure 4). Most of these products are exported to the rest of the Netherlands or abroad. If the dairy sector in Overijssel would only produce what is demanded in the urban areas, the herd of dairy could be reduced by approximately $80 \%$. The production of greenhouse gas emissions from dairy would then reduce with an approximately similar percentage. 


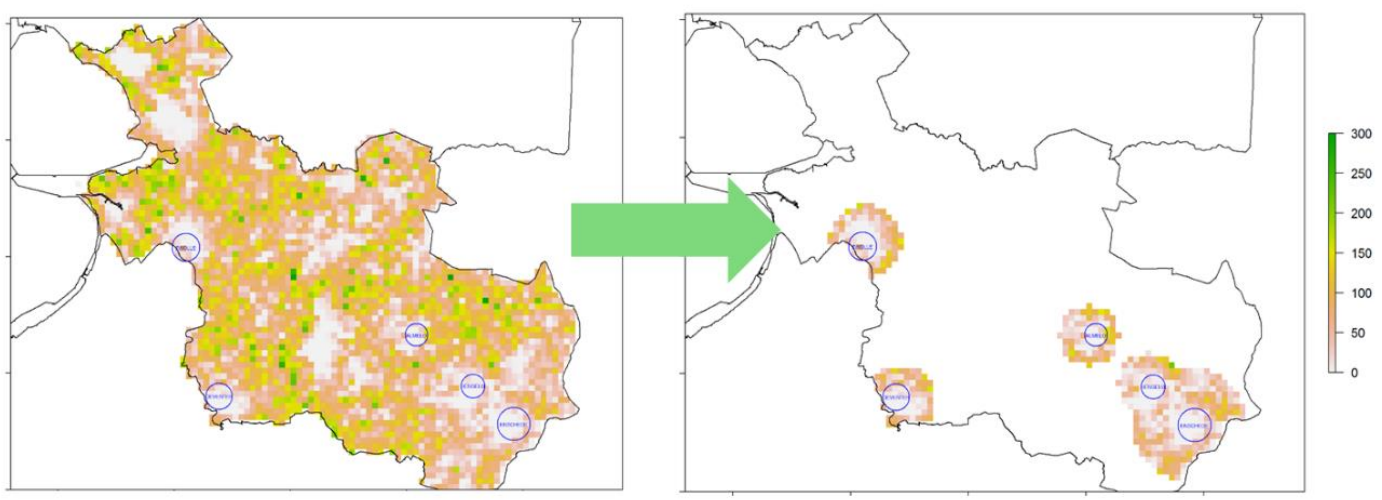

(green color means 300 cows per $\mathrm{km}^{2}$ or more)

Figure 4. Virtual production maps (number of dairy cows per $\mathrm{km}^{2}$ ) for dairy production in the province of Overijssel, the Netherlands (Source: authors derived from [27]).

This case shows that stakeholder meetings for transitions can be dynamic with respect to the opinions and input of stakeholders. By linking spatial decision support tools with stakeholder participation, the scope and focus of the discussions as well as the employment of decision support tools shifted over time. Departing from a sectoral perspective on sustainable dairy production, the scope of discussion eventually broadened towards a more integral perspective with a focus not only on spatial, economic and environmental dimensions, but also on healthy consumption. Stakeholders contributed when the topic of a meeting linked up with their interest. Although switching participation of stakeholders was a point of concern for the continuity of discussion, stakeholders appreciated that experts at different levels-from consumer to producer-were involved and gave input during the workshops.

\subsection{Urban Food Security in Accra, Ghana}

In Ghana, food security has been an important topic of discussion in rural as well as in urban areas. In the metropolitan region of Accra there is high dietary diversity but low consumption of foods rich in micronutrients, such as fruits and milk and other dairy products-especially among women, poor households and the non-educated [49]. In 2000, 32\% of households' budget in Accra was spent on food, and in poorer neighborhoods, this share was even higher [50]. Moreover, the low quality of the food sold and lack of hygiene during food preparation and sale can contribute to food insecurity [51].

Due to both rapid urbanization and climate change, improving future food security in Ghana will lead to new challenges in urban areas [52]. It is projected that there will be a major urbanization trend in Ghana, which implies migration from rural to urban areas and a rapid growth of the population of Accra, which had 4 million inhabitants in 2017. Moreover, the agricultural production is expected to suffer from climate change impacts, with land potentially becoming unusable for agricultural practices [53]. This combination of developments raises concerns about the future food security in the metropolitan area of Accra.

Employing the TSS approach, a meeting with regional experts on urban food security was organized in November 2018 in order to explore what the most issues were in the Accra metropolitan area. This included a discussion of future projections of different Shared Socioeconomic Pathways (SSPs) developed by the IPCC (Intergovernmental Panel on Climate Change). An example of this is the Shared Socioeconomic Pathways (SSP) approach from IPCC [54]. With the global economic model MAGNET (Modular Applied GeNeral Equilibrium Tool) [15,16], different future projections of demographics, food production, food demand and food security in Ghana and in Accra in particular were explored. 
To explore this food security, two food commodities were selected: (i) vegetables and fruit (including nuts), which are advocated for their nutritional values and are widely cropped in Ghana; and (ii) rice, which is one of the dominating cereals in the diet of Ghana's population. The main issue for urban food security is how the consumption of these commodities will develop under different scenarios and whether Ghana can stay self-supporting with respect to their production of these commodities. This was explored through virtual production maps based on the results of projections with the global economic model MAGNET, see for more details on databases and software use [55].

The virtual production maps of Accra were obtained with an iterative procedure to search for production areas in the vicinity of Accra, so that supply of commodities would meet the demand in the Accra area. Figure 5 shows an example of vegetable and fruit production projections under the Ecotopia scenario in 2010, 2030 and 2050 [55]. In 2010, the virtual production circle of vegetables and fruits for a self-sufficient greater Accra was a $35 \mathrm{~km}$ radius (area of 56,900 ha and 5.9 million people living in this circle). With time, the area required to suffice the demand for vegetables and fruit in greater Accra under the Ecotopia scenario increased gradually. In addition, the area for fruit and vegetables production per grid cell decreases as the areas are turning increasingly green from panel (a) to (c) in Figure 5-see [55] for more elaborated analyses.

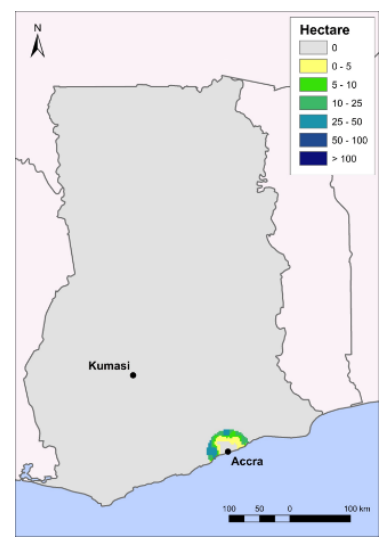

(a)

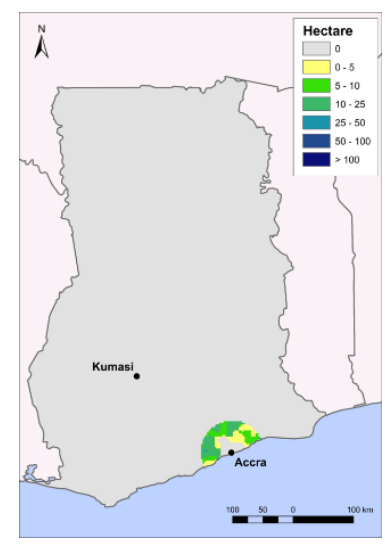

(b)

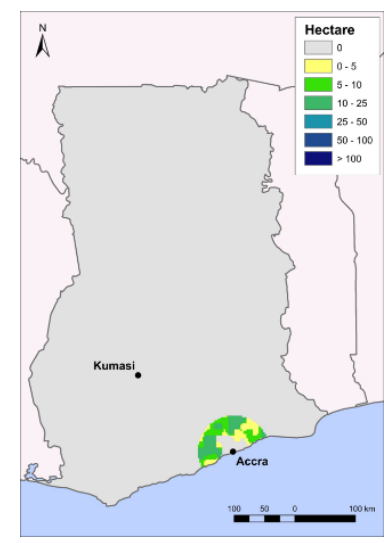

(c)

Figure 5. Virtual production maps (ha per grid cell) of vegetables and fruit in 2010 (a), 2030 (b), and 2050 (c) under the Ecotopia scenario with a fixed radius around Accra, Ghana [55].

In the expert meeting these maps were discussed. As the experts were traditionally involved in value chain analysis of particular commodities and not food consumption and diets, these maps were new. Experts shared their knowledge and experiences within the perspective of future projections. With the experts, it was discussed what would be the most desirable future from the food security perspective, and how the transition to this future could be addressed by a broader groups of stakeholders.

\section{Discussion and Conclusions}

Metropolitan areas are highly complex systems where safeguarding food security is not merely a shift in consumer preferences or in food production but encompasses a systematic change in the whole food chain from the primary producer up to the end-consumer [26]. In this article, we have introduced the Transition Support System approach to identify action perspectives that can contribute towards establishing sustainable food security in metropolitan areas. The TSS approach does not provide readily available solutions for improving urban food security, but rather advocates the involvement of both stakeholders and experts in the process of looking for these solutions. It therefore promotes a stakeholder-inclusive approach to decision making in food system transitions. In order to do so, decision support tools and participatory processes are mutually employed to support moving towards urban food security. This transition is a complex, long-term process that involves many stakeholders. 


\subsection{Employing the TSS Approach}

We have applied the TSS approach in two food system case studies with contrasting contexts: Accra (Ghana) and the province of Overijssel (the Netherlands). While both cases represent a complex situation in the early stages of a potential transition process, they illustrate how a combination of expert knowledge and decision support can contribute towards the development of new and innovative perspectives on urban food security. As a transition arises through a combined effort of diverse actors within and outside of formal boundaries, the involvement of stakeholders in processes of societal change has helped to build a joint agenda towards the future, but also in better understanding of the issues at stake by both stakeholders and scientific experts. The latter is in line with findings by Metzger et al. that highlighted how such interaction provides policy-makers and stakeholders with guidance for policy development, planning and management [47].

The application in two contrasting case studies (Overijssel in the Netherlands and Accra in Ghana) confirmed the need to start the TSS approach with developing awareness and the added value of mapping the urgency of pressing issues on food security. This helped to identify a group of stakeholders who were invited to engage in the TSS process-and most of them responded positively. This positive response of many stakeholders as well as their contributions in different sessions emphasize that they indeed worried about urban food security. However, the involvement of stakeholders requires somebody to take the initiative and organization in order to establish a joint discussion and progress from this into an ongoing process to promote urban food security. The challenge in this is to combine central steering with an "open structure" where stakeholders feel invited and motivated to participate and bring in their own ideas: a combination of "bottom-up" and "top-down"-something for which both authorities and stakeholders are searching in urban governance [56].

To progress from a sense of urgency towards a vision for food secure cities, the application of several scenario-based tools helped to provide valuable insight into people's views of the desired future. To advance from these visions of desirable futures towards an assessment of the potential impacts of various scenarios, spatial analyses through a variety of models supported stakeholders. In both cases, the benefit of employing decision support models was clearly experienced during discussions. The possibility to work with these models in a live setting provided tailor made visual insights for stakeholders into the effects of different courses of action, which contributed towards their understanding of the impacts of such actions. The case studies were in the initial phase of a potential transition. In needs to be kept in mind that it is important to also monitor the effects or interventions during and after these have been employed in practices. This will allow to adapt the strategy in the future, since aiming for societal change requires constant evaluation and adaptation in governance [39].

Regarding the specific lessons offered by these case studies, we want to emphasize that the case studies are unique and somewhat contrasting in nature. The case studies do offer important lessons and they illustrate how the TSS approach can be employed, but what works in one specific context does not necessarily do so in another. Therefore, our TSS approach can be applied elsewhere, although the local or regional context and needs of stakeholders involved should always be the point of departure. In line with principles propagated by scholars in reflexive evaluation and transition management, transferability thus requires flexibility, reflexivity and sensitivity to the local context $[20,32,36]$.

\subsection{A Comparison of the TSS Approach with Other Approaches to Steer Societal Transitions}

On a meta-level, a comparison of the TSS approach vis-a-vis a number of other approaches that aim to steer complex societal transitions reveals a number of parallels and distinctions. Like reflexive evaluation and transition management, the TSS approach does not depart from a linear perspective on societal transitions. Rather, it recognizes that the pathway towards such a transition is complex and that steering towards societal change is an iterative process. Concerning the research methodologies which the TSS approach employs, it integrates a "traditional" decision support perspective with stakeholder participation and deliberation from a qualitative perspective. These stakeholders are actively involved in the process of research as advocated by scholars in the fields of reflexive evaluation and transition 
management. As in reflexive evaluation and in some applications of transition management, scientists play a role in facilitating this interaction, but also in providing decision support that is closely linked with stakeholder expertise.

Our TSS approach is thus closely related to various aspects that are emphasized in transition management, reflexive evaluation and decision support tools, but it also has a number of distinctive features in relation to each of these approaches. The focus on decision support adds a data driven perspective which projects the impact of certain courses of action or policy decisions, providing a guidance to stakeholders as well as valuable input for discussion. By incorporating the iterative and step-wise process of joint innovation and reflection which is central in reflexive evaluation, it adds a focus on joint learning as a pathway to knowledge creation and adoption of solutions for urban food security in comparison to decision support tools and transition management. Finally, the integral scope, multi-method perspective and focus on stakeholders as innovators, all emphasized in transition management, contribute towards an action perspective for promoting urban food security through the engagement of scientists as well as stakeholders, something which is lacking in decision support tools and that broadens the methodological scope of reflexive evaluation.

\subsection{Towards Urban Food Security}

In line with observations by others, the above two case studies have illustrated that societal change towards food security is a non-linear, iterative, multi-stakeholder process in which diverse societal forces come together $[20,21]$. The literature has highlighted how stakeholders struggle to significantly affect the city and the urban environment as a whole in order to promote societal change [57]. It has also been shown how authorities are still searching for proper ways to connect to various stakeholders and "steer" the fragmented efforts of societal actors towards a more structural transition $[56,58]$. Since a transition arises through a combined effort of diverse stakeholders, the issue of urban food security demands authorities and scientists to engage with a broad range of stakeholders in order to address and promote potential solutions.

Our TSS approach provides inspiration for how this can be done, but should not be seen as a strict framework to be applied "as is": it is important to incorporate the preferences of stakeholders in organizing the governance process and tailor the employment of decision support tools to the local context. Those employing the TSS or other frameworks to promote urban food security need to do so with a degree of flexibility in order to tailor research to the preferences of stakeholders, the political and ecological context, and the specific food security issues at stake.

In this, our review of the literature in Section 3 as well as our empirical work in Section 5 of this article have illustrated that a combination of stakeholder-based and science-based methods is necessary in order to link scientific knowledge on food security with stakeholder aims and expertise, promoting sustainable transitions that are better embedded in society. Promoting a transition in the urban food system requires joint learning and reflexive evaluation in order to adapt governance to what is happening in society. In promoting urban food security, we strongly believe that research institutes should go beyond their role as merely "suppliers of knowledge", but also have a role as a supporting actor in a broader process of change, engaging with a variety of societal stakeholders. After all, we as scientists are but one of many actors who have a stake in the urban food system. Working together with farmers, farm advisors and suppliers, NGOs and citizen groups, brokers, retail-stores, food transporters, food consumers, and authorities can also help us to better understand the issues at stake, promote tailored solutions and increase the impact of our work.

Author Contributions: Conceptualization, M.D.-D., N.P.; Investigation, M.D.-D., V.L., T.J.M.M.; Methodology, M.D.-D., N.P.; Visualization, M.D.-D., N.P.; Writing—original draft, M.D.-D.; V.L., T.J.M.M., N.P.; Writing—review \& editing, M.D.-D., V.L., T.J.M.M., N.P. All authors have read and agreed to the published version of the manuscript.

Funding: This research and the Article Processing Charge have both been funded by the Dutch Ministry of Agriculture, Nature and Food Quality, grant numbers KB-25-009-003/ KB-35-006-001. 
Acknowledgments: We wish to thank all scientific experts, colleagues and regional stakeholders who have contributed to the development of the Transition Support System and its application in practice. We want to thank Wil Hennen and Vasco Diogo for their contribution in visualizing Figures 4 and 5, Harry Kortstee for his contribution to organizing the workshop in the province of Overijssel, The Netherlands.

Conflicts of Interest: The authors declare no conflict of interest.

\section{References}

1. Zhou, Y.; Varquez, A.C.G.; Kanda, M. High-resolution global urban growth projection based on multiple applications of the SLEUTH urban growth model. Sci. Data 2019, 6, 34. [CrossRef] [PubMed]

2. Grafakos, S.; Gianoli, A.; Tsatsou, A. Towards the Development of an Integrated Sustainability and Resilience Benefits Assessment Framework of Urban Green Growth Interventions. Sustainability 2016, 8, 461. [CrossRef]

3. United Nations. The New Urban Agenda; United Nations: New York, NY, USA, 2016; p. 66.

4. Filippini, R.; Marraccini, E.; Houdart, M.; Bonari, E.; Lardon, S. Food production for the city: Hybridization of farmers' strategies between alternative and conventional food chains. Agroecol. Sustain. Food Syst. 2016, 40, 1058-1084. [CrossRef]

5. Filippini, R.; Lardon, S.; Bonari, E.; Marraccini, E. Unraveling the contribution of periurban farming systems to urban food security in developed countries. Agron. Sustain. Dev. 2018, 38, 21. [CrossRef]

6. FAO. Rome Declaration and Plan of Action. In Proceedings of the World Food Summit, Rome, Italy, 13-17 November 1996.

7. Battersby, J.; Haysom, G. Urban Food Security. In Urban Geography in South Africa; Massey, R., Gunter, A., Eds.; GeoJournal Library; Springer: Cham, Switzerland, 2020; pp. 251-263. ISBN 978-3-030-25368-4.

8. Linderhof, V.; Vlijm, R.; Pinto Diogo, V.; Raaijmaker, W.; Dijkshoorn-Dekker, M. Urban Food Security in Ghana: A Policy Review; WEcR Report 2019-057b; Wageningen Economic Research: The Hague, The Netherlands, 2019.

9. Food and Agriculture Organization of the United Nations. Milan Urban Food Policy Pact Urban Food Policy Framework for Action; Food and Agriculture Organization of the United Nations: Rome, Italy, 2015.

10. Magarini, A.; Porreca, E. European Cities Leading in Urban Food Systems Transformation: Connecting Milan $\mathcal{E}$ Food 2030; European Commission: Brussels, Belgium, 2019; ISBN 978-92-76-00042-6.

11. Kanter, D.R.; Schwoob, M.-H.; Baethgen, W.E.; Bervejillo, J.E.; Carriquiry, M.; Dobermann, A.; Ferraro, B.; Lanfranco, B.; Mondelli, M.; Penengo, C.; et al. Translating the Sustainable Development Goals into action: A participatory backcasting approach for developing national agricultural transformation pathways. Glob. Food Secur. 2016, 10, 71-79. [CrossRef]

12. Veldhuizen, L.J.L.; Giller, K.E.; Oosterveer, P.; Brouwer, I.D.; Janssen, S.; van Zanten, H.H.E.; Slingerland, M.A. The Missing Middle: Connected action on agriculture and nutrition across global, national and local levels to achieve Sustainable Development Goal 2. Glob. Food Secur. 2020, 24, 100336. [CrossRef]

13. Snyder, H. Literature review as a research methodology: An overview and guidelines. J. Bus. Res. 2019, 104, 333-339. [CrossRef]

14. Swanborn, P. Case Study Research: What, Why and How? SAGE Publications, Inc.: London, UK, 2010; ISBN 978-1-84920-612-9.

15. Shutes, L.; Verma, M.; Kuiper, M. Changing Diets in a Changing World: Assessing the Impact of Urbanisation on Agriculture; Wageningen Economic Research: The Hague, The Netherlands, 2015.

16. Kuiper, M.; Shutes, L.; Oudendag, D. With Food and Nutrition Security Hinging on Inequality, Labour Allocation beyond Agriculture Proves a Neglected Key Driver in Long Term FNS Projections; Wageningen Economic Research: The Hague, The Netherlands, 2017.

17. Geels, F.W.; Schot, J. Typology of sociotechnical transition pathways. Res. Policy 2007, 36, 399-417. [CrossRef]

18. Rip, A.; Kemp, R. Technological change. In Human Choices and Climate Change 2; Rayner, S., Malone, E., Eds.; Battelle: Columbus, OH, USA, 1998; pp. 327-399.

19. Wolfram, M.; Frantzeskaki, N. Cities and systemic change for sustainability: Prevailing epistemologies and an emerging research agenda. Sustainability 2016, 8. [CrossRef]

20. Fischer, A.R.H.; Beers, P.J.; van Latesteijn, H.; Andeweg, K.; Jacobsen, E.; Mommaas, H.; van Trijp, H.C.M.; Veldkamp, A. Transforum system innovation towards sustainable food. A review. Agron. Sustain. Dev. 2012, 32, 595-608. [CrossRef] 
21. Frantzeskaki, N.; Dumitru, A.; Anguelovski, I.; Avelino, F.; Bach, M.; Best, B.; Binder, C.; Barnes, J.; Carrus, G.; Egermann, M.; et al. Elucidating the changing roles of civil society in urban sustainability transitions. Curr. Opin. Environ. Sustain. 2016, 22, 41-50. [CrossRef]

22. Loorbach, D. Transition management for sustainable development: A prescriptive, complexity-based governance framework. Governance 2010, 23, 161-183. [CrossRef]

23. Spaargaren, G. Sustainable consumption: A theoretical and environmental policy perspective. Soc. Nat. Resour. 2003, 16, 687-701. [CrossRef]

24. Buizer, M.; Elands, B.H.M.; Mattijssen, T.J.M.; van der Jagt, A.; Ambrose-Oji, B.; Gerőházi, E.; Santos, A.; Steen Møller, M. The Governance of Urban Green Spaces in Selected EU-Cities; Green Surge: Copenhagen, Denmark, 2015.

25. Nielsen, J.; Farrelly, M.A. Conceptualising the built environment to inform sustainable urban transitions. Environ. Innov. Soc. Transit. 2019, 33, 231-248. [CrossRef]

26. Poppe, K.J.; Termeer, C.; Slingerland, M. Transitions towards Sustainable Agriculture and Food Chains in Peri-Urban Areas; Wageningen Academic Publishers: Wageningen, The Netherlands, 2009.

27. Dijkshoorn-Dekker, M.; Kortstee, H.; Linderhof, V. Creating a Sustainable Food System Together: The Application of the Transition Support System Approach in the Dutch Province of Overijssel; WEcR Report 2019-091; Wageningen Economic Research: The Hague, The Netherlands, 2019.

28. Nordström, E.-M.; Nieuwenhuis, M.; Başkent, E.Z.; Biber, P.; Black, K.; Borges, J.G.; Bugalho, M.N.; Corradini, G.; Corrigan, E.; Eriksson, L.O.; et al. Forest decision support systems for the analysis of ecosystem services provisioning at the landscape scale under global climate and market change scenarios. Eur. J. For. Res. 2019, 138, 561-581. [CrossRef]

29. Pokrivcak, J.; van Berkum, S.; Drgova, L.; Mraz, M.; Ciaian, P. The role of non-tariff measures in EU dairy trade with Russia. Post Communist Econ. 2013, 25, 175-189. [CrossRef]

30. Hajer, M.; Nilsson, M.; Raworth, K.; Bakker, P.; Berkhout, F.; de Boer, Y.; Rockström, J.; Ludwig, K.; Kok, M. Beyond cockpit-ism: Four insights to enhance the transformative potential of the sustainable development goals. Sustainability 2015, 7, 1651-1660. [CrossRef]

31. Sali, G.; Monaco, F.; Mazzocchi, C.; Corsi, S. Exploring Land Use Scenarios in Metropolitan Areas: Food Balance in a Local Agricultural System by Using a Multi-objective Optimization Model. Agric. Agric. Sci. Procedia 2016, 8, 211-221. [CrossRef]

32. Halbe, J.; Pahl-Wostl, C. A methodological framework to initiate and design transition governance processes. Sustainability 2019, 11. [CrossRef]

33. Smith, G. Democratic Innovations: Designing Institutions for Citizen Participation; Theories of Institutional Design; Oxford University Press: Oxford, UK, 2009.

34. Kenis, A.; Bono, F.; Mathijs, E. Unravelling the (post-)political in transition management: Interrogating pathways towards sustainable change. J. Environ. Policy Plan. 2016, 18, 568-584. [CrossRef]

35. Eshuis, J.; Braun, E.; Klijn, E.H.; Zenker, S. The differential effect of various stakeholder groups in place marketing. Environ. Plan. C Politics Space 2018, 36, 916-936. [CrossRef]

36. Stirling, A. Analysis, participation and power: Justification and closure in participatory multi-criteria analysis. Land Use Policy 2006, 23, 95-107. [CrossRef]

37. Rich, K.M.; Rich, M.; Dizyee, K. Participatory systems approaches for urban and peri-urban agriculture planning: The role of system dynamics and spatial group model building. Agricult. Syst. 2016. [CrossRef]

38. Dijkshoorn-Dekker, M.W.C.; Polman, N.B.P.; Bogaardt, M.J.; Soma, K.; Daane, A. Inclusive Metropolitan Transitions; Challenges and Opportunities for Food and Green; Wageningen Economic Research: The Hague, The Netherlands, 2017.

39. Van Mierlo, B.; Arkesteijn, M.; Leeuwis, C. Enhancing the Reflexivity of System Innovation Projects With System Analyses. Am. J. Eval. 2010, 31, 143-161. [CrossRef]

40. Rotmans, J.; Kemp, R.; Van Asselt, M. More evolution than revolution: Transition management in public policy. Foresight 2001, 3, 15-31. [CrossRef]

41. Regeer, B.J.; Hoes, A.-C.; van Amstel-van Saane, M.; Caron-Flinterman, F.F.; Bunders, J.F.G. Six Guiding Principles for Evaluating Mode-2 Strategies for Sustainable Development. Am. J. Eval. 2009, 30, 515-537. [CrossRef]

42. Chen, K.H.-J. Contextual influence on evaluation capacity building in a rapidly changing environment under new governmental policies. Eval. Progr. Plan. 2017, 65, 1-11. [CrossRef] 
43. Turnhout, E. The Politics of Environmental Knowledge. Conservat. Soc. 2018, 16, 363. [CrossRef]

44. Jhagroe, S.; Loorbach, D. See no evil, hear no evil: The democratic potential of transition management. Environ. Innov. Soc. Transit. 2015, 15, 65-83. [CrossRef]

45. Mertens, D. Inclusive evaluation: Implications of transformative theory for evaluation. Am. J. Eval. 1999, 20, 1-14. [CrossRef]

46. Dijkshoorn-Dekker, M. Transition Support System Approach; Wageningen Economic Research: The Hague, The Netherlands, 2018.

47. Metzger, M.J.; Rounsevell, M.D.; Heiligenberg, H.A.V.D.; Pérez-Soba, M.; Hardiman, P.S. How personal judgment influences scenario development: An example for future rural development in Europe. Ecol. Soc. 2010, 15. Available online: http://www.ecologyandsociety.org/vol15/iss2/art5 (accessed on 1 July 2020). [CrossRef]

48. Provincie Overijssel. Omgevingsvisie Overijssel 2017. Beken Kleur; Provincie Overijssel: Zwolle, The Netherlands, 2017.

49. Codjoe, S.N.A.; Okutu, D.; Abu, M. Urban Household Characteristics and Dietary Diversity: An Analysis of Food Security in Accra, Ghana. Food Nutr. Bull. 2016, 37, 202-218. [CrossRef] [PubMed]

50. Maxwell, D.G. Urban Livelihoods and Food and Nutrition Security in Greater Accra, Ghana; Research Report; International Food Policy Research Institute: Washington, DC, USA, 2000; ISBN 978-0-89629-115-7.

51. Obosu-Mensah, K. Changes in Official Attitudes Towards Urban Agriculture in Accra. Afr. Stud. Quart. 2002, 6, 19-32.

52. Szabo, S. Urbanisation and Food Insecurity Risks: Assessing the Role of Human Development. Oxf. Dev. Stud. 2016, 44, 28-48. [CrossRef]

53. Serdeczny, O.; Adams, S.; Baarsch, F.; Coumou, D.; Robinson, A.; Hare, W.; Schaeffer, M.; Perrette, M.; Reinhardt, J. Climate change impacts in Sub-Saharan Africa: From physical changes to their social repercussions. Reg. Environ. Chang. 2017, 17, 1585-1600. [CrossRef]

54. Riahi, K.; van Vuuren, D.P.; Kriegler, E.; Edmonds, J.; O’Neill, B.C.; Fujimori, S.; Bauer, N.; Calvin, K.; Dellink, R.; Fricko, O.; et al. The Shared Socioeconomic Pathways and their energy, land use, and greenhouse gas emissions implications: An overview. Glob. Environ. Chang. 2017, 42, 153-168. [CrossRef]

55. Dijkshoorn-Dekker, M.; Linderhof, V.; Pinto, V.; Hennen, W.; Oudendag, D.; Kuiper, M.; Shutes, L. Transition Support System Approach for Urban Food Security in the Future: The Case of Ghana; WEcR Report 2019-057a; Wageningen Economic Research: The Hague, The Netherlands, 2019.

56. Buijs, A.E.; Hansen, R.; Van der Jagt, S.; Ambrose-Oji, B.; Elands, B.H.M.; Rall, E.; Mattijssen, T.J.M.; Pauleit, S.; Runhaar, H.A.C.; Stahl Olafsson, A.; et al. Mosaic governance for urban green infrastructure: Upscaling active citizenship from a local government perspective. Urb. For. Urb. Green. 2018, 40, 53-62. [CrossRef]

57. Mattijssen, T.J.M.; Buijs, A.A.E.; Elands, B.H.M.; Arts, B.J.M.; van Dam, R.I.; Donders, J.L.M. The Transformative Potential of Active Citizenship: Understanding Changes in Local Governance Practices. Sustainability 2019, 11, 5781. [CrossRef]

58. Franklin, A.; Marsden, T. (Dis)connected communities and sustainable place-making. Local Environ. 2015, 20, 940-956. [CrossRef]

(C) 2020 by the authors. Licensee MDPI, Basel, Switzerland. This article is an open access article distributed under the terms and conditions of the Creative Commons Attribution (CC BY) license (http://creativecommons.org/licenses/by/4.0/). 